\title{
Lipophilization of Phenolic Acids through Esterification Using $p$-toluenesulfonic Acid as Catalyst
}

\author{
CHEN Jingnan, LIU Wei*
}

School of Food Science and Technology, Henan University of Technology, Zhengzhou 450001, China

\begin{abstract}
Lipophilic antioxidants are used in edible oils and oleaginous foods. Therefore, development of novel lipophilic antioxidant is very important. $p$-toluenesulfonic acid (PTSA) catalyzed esterification of dihydrocaffeic acid (DHCA) with hexanol was selected as model reaction to investigate the synthesis of lipophilic antioxidant. The highest yield of hexyl dihydrocaffeate was achieved under the following optimum conditions: $1 \mathrm{~mol} \%$ PTSA, 1:30 molar ratio of dihydrocaffeic acid to hexanol without molecular sieves at $80^{\circ} \mathrm{C}$ in $2 \mathrm{~h}$. The relationship between temperature and the forward rate constant gave the activation energy of $22.6 \mathrm{~kJ} / \mathrm{mol}$, which indicated that PTSA possessed high catalytic activity in the synthesis of hexyl dihydrocaffeate. In addition, the activity of PTSA was not inhibited by the water produced during esterification process. Importantly, this esterification could even proceed smoothly when initial water content was below 5\%. In addition, the esterification of a set of phenolic acids could take place efficiently under the same conditions affording the corresponding esters in good to excellent yields. This established method will provide an efficient method for produce lipophilic antioxidants from various natural phenolic acids.
\end{abstract}

Keywords: Dihydrocaffeic acid; Phenolic acids; Hexanol; $p$-toluenesulfonic acid; Esterification; Antioxidant

\section{Introduction}

Phenolic acids, such as ferulic, caffeic and sinapic acids, are natural hydrophilic antioxidants, which occur in fruits, vegetables, spices and herbs. More importantly, many natural phenolic compounds have been reported to have anti-cancer, anti-atherosclerotic, anti-bacterial, anti-viral and anti-inflammatory activities ${ }^{[1-5]}$. Phenolic hydroxyl groups are often associated with their antioxidant activity. These phenolic acids have more than one hydroxyl groups and show good redox properties, which allow them to act as reducing agents, hydrogen donators and singlet oxygen quenchers. Due to their useful biological properties in food and related fields, there has been continuing research focusing on phenolic acids and related compounds in recent years.

However, the solubility of phenolic acids in hydrophobic system is limited, which restrict their applications. Incorporation of a hydrophobic group into phenolic acids such as fatty alcohol represents a possible route to improve the solubility of phenolic acids in oil-based formulas and emulsions ${ }^{[6-7]}$. In recent years, a number of studies reported the enzymatic synthesis of hydrophobic derivatives of phenolic acids to increase their oil-solubility and their antioxidant activity ${ }^{[6-9]}$. Though lipase catalysis can be conducted under mild reaction conditions, long reaction time (24-48 h), expensive price and sensitive lipase reagents limit their wide applications. Recently, it has been proved that

Received: 15 November 2017 /Accepted: 17 January 2018.

Supported by Scientific and Technological Project of Henan Province (No. 182102110024) and Basic Research Funds of Henan University of Technology (No. 2015RCJH01).

*Corresponding author. E-mail: liuwei307@hotmail.com

OHenan University of Technology 2018

CHEN J N, LIU W. Lipophilization of Phenolic Acids through Esterification Using $p$-toluenesulfonic Acid as Catalyst[J]. Grain \& Oil Science and Technology, 2018, 1(2): 91-96. $p$-toluenesulfonic acid (PTSA) has the potential to be used as a catalyst in conventional acidic catalytic system ${ }^{[10-13]}$. PTSA is characterized by the mildness of reaction conditions, inexpensive chemical and excellent functional group tolerance, which could afford the corresponding phenolic acid esters in high yields ${ }^{[10]}$.

We have noticed that lipase has been successfully applied in lipophilization of dihydrocaffeic acid with hexanol to increase oil-solubility and antioxidant activity, albeit requiring long reaction time $(48-72 \mathrm{~h})^{[6]}$. The present study aimed to investigate the esterification reaction of dihydrocaffeic acid with hexanol using PTSA as catalysts, which would exhibit excellent potential for the rapid lipophilisation of dihydrocaffeic acid. And a set of other phenolic acids were also studied using this convenient reaction system, under which the corresponding phenolic acid esters could be prepared to excellent yields. The present study will provide a simple and efficient method for lipophilization of phenolic acids.

\section{Materials and methods}

\subsection{Materials}

Dihydrocaffeic acid (purity $>98.0 \%$ ), ferulic acid (purity $>98.0 \%$ ), caffeic acid (purity $>98.0 \%$ ), sinapic acid (purity $>$ $98.0 \%$ ) and gallic acid (purity $>98.0 \%$ ) were purchased from Sigma-Aldrich (China); hexanol (purity $>99.0 \%$ ) was purchased from Alfa Aesar Chemical Co., Ltd. (China); $p$-toluenesulfonic acid (purity $=99 \%$ ) was purchased from Sinopharm Chemical Reagent Co., Ltd. (China); Methanol and molecular sieve (4A) were purchased from Tianjin Kemiou Chemical Reagent Co., Ltd. (China).

\subsection{Typical Experimental Procedure for Synthesis of Hexyl Dihydrocaffeate}

Dihydrocaffeic acid and hexanol were added into a $10 \mathrm{~mL}$ reaction tube and the reaction was initiated by the addition of 
a certain amount of $p$-toluenesulfonic acid. The mixture was stirred for $6 \mathrm{~h}$ at indicated temperature in oil bath. After the reaction finished, the mixture was cooled to room temperature and the excess hexanol was removed by evaporation under reduced pressure. Then the product was extracted with ethyl acetate, washed with saturated sodium chloride $(\mathrm{NaCl})$ brine and dried by anhydrous sodium sulfate $\left(\mathrm{Na}_{2} \mathrm{SO}_{4}\right)$. Then the mixture was filtered to remove the drier. After the solvent evaporation under reduced pressure, the crude product was obtained. Hexyl dihydrocaffeate was purified using column chromatography method, while the mixture of chloroform and methanol as eluants (100:1 ratio of chloroform and methanol), and then pure hexyl dihydrocaffeate was isolated.

\subsection{HPLC Analysis}

$10 \mu \mathrm{L}$ aliquots of the well-stirred reaction mixture were withdrawn at intervals for HPLC analysis. The reactants were analyzed using HPLC (Waters 2695) with a C18 reverse phase column $(4.6 \times 150 \mathrm{~mm}, 3.5 \mu \mathrm{m})$ at $30^{\circ} \mathrm{C}$, and eluted with a binary ingredient of solvent $\mathrm{A}$ (water containing $0.5 \%$ glacial acetic acid) and solvent $B(100 \%$, methanol) at $0.8 \mathrm{~mL} / \mathrm{min}$. Isocratic elution was adopted with the volume ratio of $\mathrm{A}$ and $\mathrm{B}$ 35:65. UV detection wavelength was at $280 \mathrm{~nm}$. The conversion of dihydrocaffeic acid (DHCA) and yield of hexyl dihydrocaffeate were quantified by external standard method.

\subsection{Statistical Analysis}

Experimental results were obtained as means \pm standard deviation $(n=3)$.

\section{Results and Discussion}

\subsection{Effect of Catalyst Loading on the Yield of Hexyl Dihydrocaffeate}

As an efficient esterification catalyst, catalyst loading of PTSA is one of the most important parameters affecting the conversion of DHCA and the yield of hexyl dihydrocaffeate. We carried out the investigation under such reaction conditions: DHCA $1.0 \mathrm{mmol}$, hexanol $30.0 \mathrm{mmol}$, molecular sieve $300 \mathrm{mg} / \mathrm{mL}$ and $80{ }^{\circ} \mathrm{C}$. The effect of catalyst loading on the conversion of DHCA and yield of hexyl dihydrocaffeate is shown in Fig. 1. As amount of PTSA was increased from $0.1 \%$ to $1 \%$, conversion of dihydrocaffeic acid increased from $15.9 \%$ $(15 \mathrm{~min})$ to $37.0 \%(6 \mathrm{~h})$ and from $81.4 \%(15 \mathrm{~min})$ to $99.5 \%$ $(6 \mathrm{~h})$, while the yield of hexyl dihydrocaffeate increased from $12.2 \%(15 \mathrm{~min})$ to $31.8 \%(6 \mathrm{~h})$ and from $79.8 \%(15 \mathrm{~min})$ to $99.3 \%$ (6 h), respectively. Furthermore, continually increasing the amount of PTSA to $2 \%$ led to the conversion of DHCA from $95.2 \%(15 \mathrm{~min})$ to $99.7 \%(6 \mathrm{~h})$ and yield of hexyl dihydrocaffeate from $94.2 \%$ (15 $\mathrm{min}$ ) to $99.7 \%$ (6 h). It was concluded that this esterification reaction was fast enough in the presence of $1.0 \%$ PTSA and excess amount of catalyst (2\%) would not further promote this esterification process. And catalyst loading less than $1.0 \%$ showed less efficiency on conversion of DHCA, so $1.0 \%$ of PTSA was the optimum catalyst loading used in the subsequent study.

\subsection{Effect of Substrate Molar Ratio on the Esterification Reaction}

The esterification reaction between DHCA and hexanol is a reversible reaction. A higher equilibrium conversion and yield can be obtained if the reverse reaction is inhibited. In this system, using excess hexanol was more convenient to shift the equilibrium toward the desired esterification product, and no more solvents were considered in our experiments.

The effect of substrate molar ratio on the conversion of DHCA and yield of hexyl dihydrocaffeate is shown in Fig. 2. As the molar ratio of DHCA to hexanol increased from 1:10 to $1: 30$, the reaction rate (in $30 \mathrm{~min}$ ) increased rapidly. When the molar ratio was 1:30, the conversion of DHCA increased from $40.0 \%$ (5 $\mathrm{min}$ ) to $99.6 \%(4 \mathrm{~h})$, and the yield of hexyl dihydrocaffeate increased from $33.7 \%$ (5 min) to $99.5 \%(4 \mathrm{~h})$, respectively. Further increasing the substrate molar ratio of DHCA to hexanol (1:50) led to a decrease in the conversion of DHCA and yield of hexyl dihydrocaffeate because the use of large excess amount of hexanol could obviously decrease the concentration of both DHCA and catalyst (PTSA), which would decrease the esterification rate. Therefore, the optimum substrate molar ratio of DHCA to hexanol was 1:30.

\subsection{Effect of Reaction Temperature on the Esterification Reaction}

Reaction temperature is one of the most important parameters affecting conversion of DHCA and yield of hexyl dihydrocaffeate during the esterification reaction. Fig. 3 shows the effect of reaction temperature $\left(40-100^{\circ} \mathrm{C}\right)$ on the conversion of DHCA and yield of hexyl dihydrocaffeate. The conversion of DHCA and yield of hexyl dihydrocaffeate increased gradually as the reaction time prolonging at different reaction temperature. At $80{ }^{\circ} \mathrm{C}$, the highest conversion and yield were obtained at 6 h. The conversion of DHCA increased from $81.4 \%$ (15 min) to $99.5 \%(2 \mathrm{~h})$ and the yield of hexyl dihydrocaffeate increased from $79.8 \%(15 \mathrm{~min})$ to $99.3 \%(2 \mathrm{~h})$ at $80^{\circ} \mathrm{C}$. Decreasing the reaction temperature $\left(40-60{ }^{\circ} \mathrm{C}\right)$ led to lower conversions. These results indicated that higher reaction temperature could activate the substrate, reduce the viscosity of the reaction mixtures and lead to a higher reaction rate. As continued to increase the reaction temperature to $100{ }^{\circ} \mathrm{C}$, the conversion of DHCA and the yield of hexyl dihydrocaffeate showed the similar results as that at $80{ }^{\circ} \mathrm{C}$. Considering the cost and efficiency, $80{ }^{\circ} \mathrm{C}$ was selected as the suitable reaction temperature and used in the subsequent optimization experiments.

\subsection{Effect of Amount of Molecular Sieves on the Esterification Reaction}

Water is the by-product of the esterification reaction of DHCA with hexanol. And removing water from the reaction system will promote esterification process and lead to higher conversion. And adding molecular sieves is one of the most efficient methods to remove water. Thus, the amount of molecular sieves is also an important factor in most esterification reactions. 


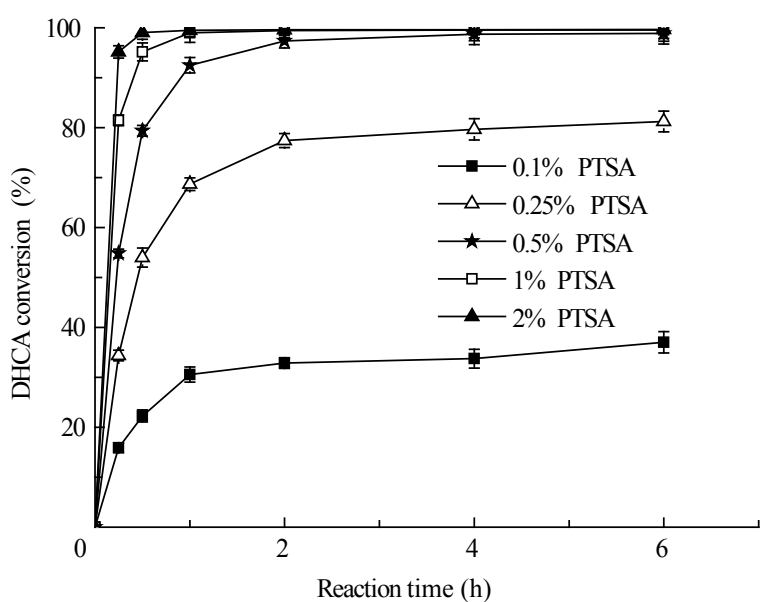

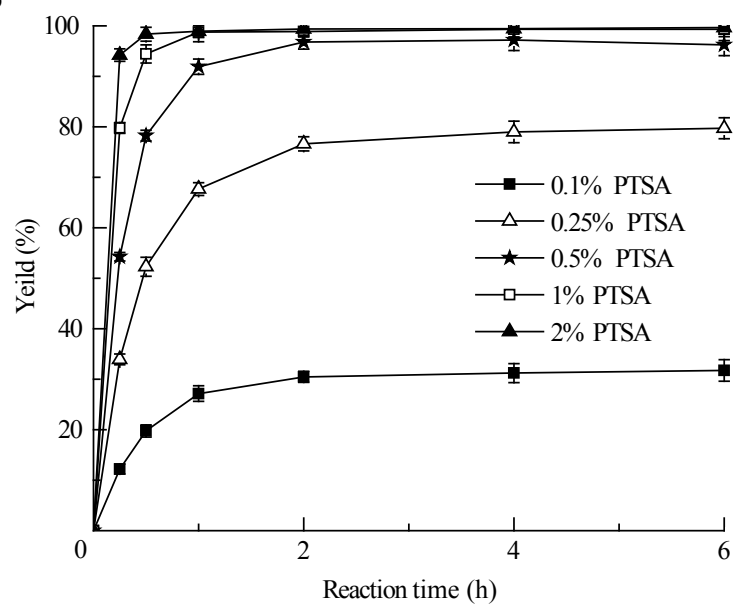

Fig. 1 Effect of TSA amount on conversion of DHCA and yield of hexyl dihydrocaffeate Reaction conditions: DHCA $1.0 \mathrm{mmol}$, hexanol $30.0 \mathrm{mmol}$, molecular sieve $300 \mathrm{mg} / \mathrm{mL}, 80^{\circ} \mathrm{C}$.
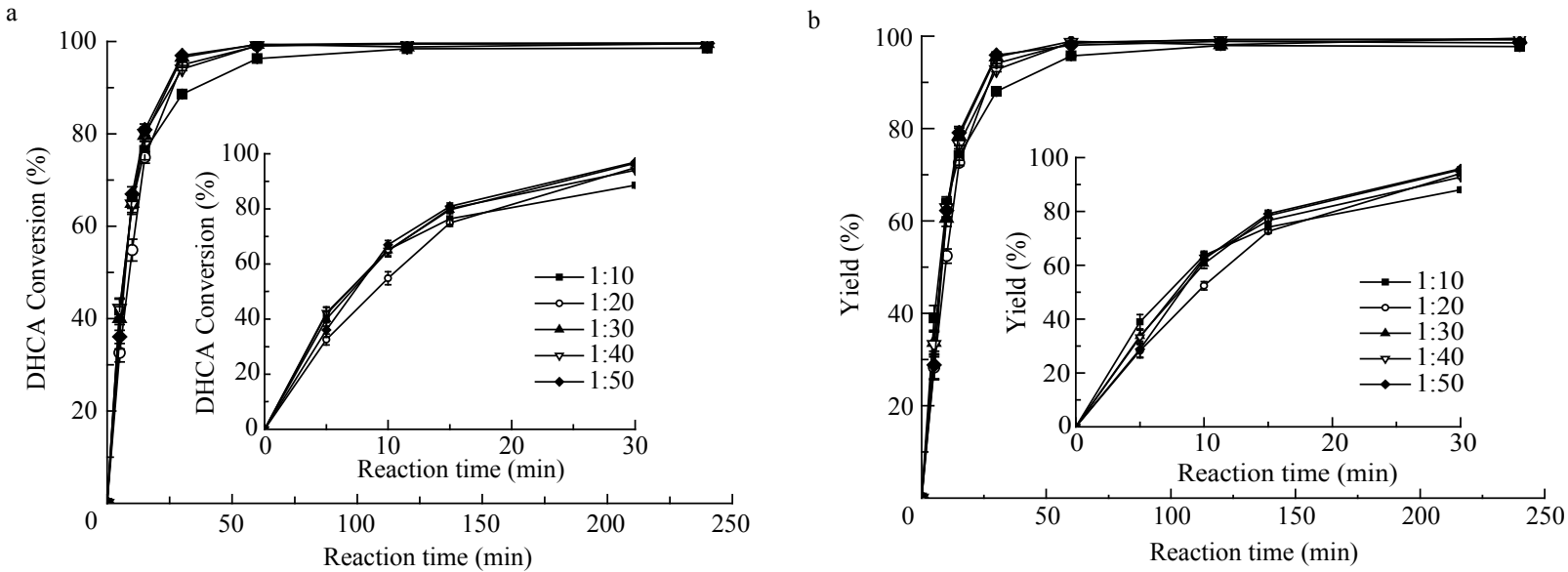

Fig. 2 Effect of substrate molar ratio on conversion of DHCA and yield of hexyl dihydrocaffeate Reaction conditions: PTSA $1 \%$, DHCA $1.0 \mathrm{mmol}$, molecular sieve $300 \mathrm{mg} / \mathrm{mL}, 80^{\circ} \mathrm{C}$.

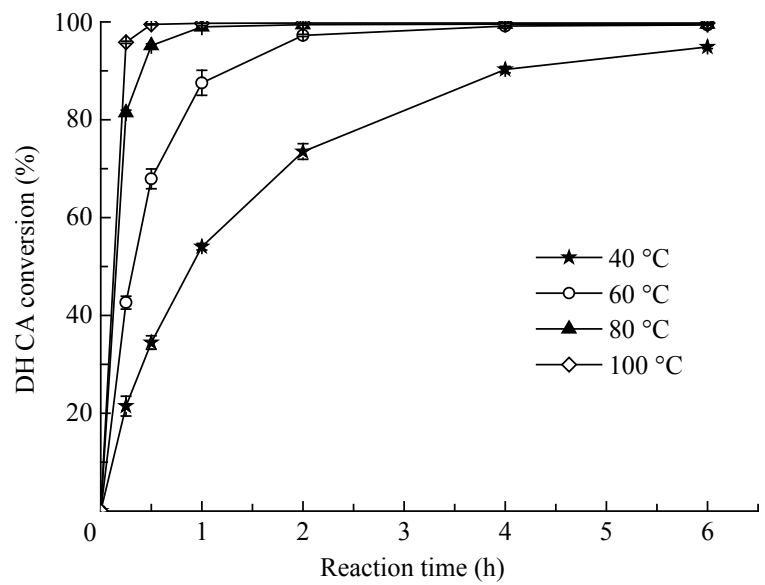

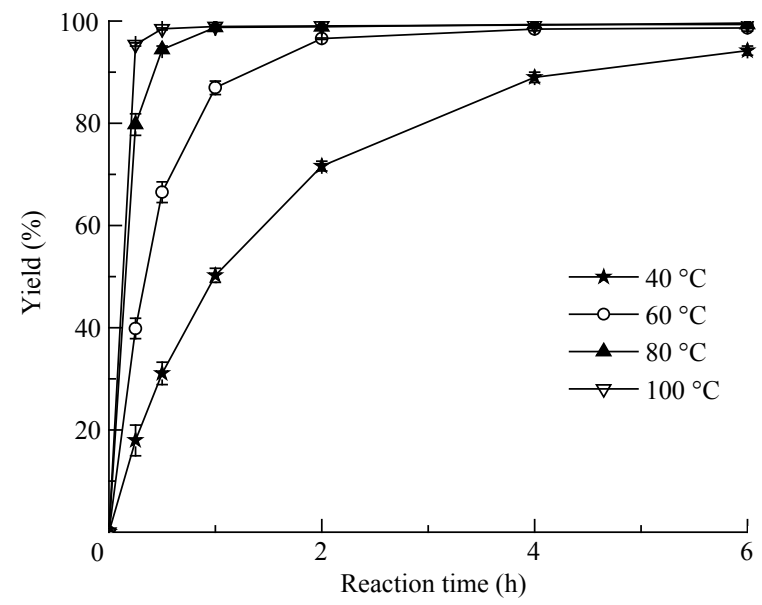

Fig. 3 Effect of reaction temperature on conversion of DHCA and yield of hexyl dihydrocaffeate Reaction conditions: PTSA 1\%, DHCA $1.0 \mathrm{mmol}$, hexanol $30.0 \mathrm{mmol}$, molecular sieve $300 \mathrm{mg} / \mathrm{mL}$. 
Fig. 4 showed that the conversion of DHCA and yield of hexyl dihydrocaffeate increased sharply within the original 2 $\mathrm{h}$, then reached equilibrium. The amount of molecular sieves $(150 \mathrm{mg} / \mathrm{mL}$ and $300 \mathrm{mg} / \mathrm{mL})$ did not have obvious influence on conversion of DHCA and yield of hexyl dihydrocaffeate. Without adding any molecular sieve, the conversion of DHCA was improved from $84.6 \%(0.25 \mathrm{~h})$ to $99.7 \%(6 \mathrm{~h})$, the yield of hexyl dihydrocaffeate was improved from $83.7 \%(0.25 \mathrm{~h})$ to $99.3 \%$ (6 h). Therefore, the employment of molecular sieves to remove the formed water was not required in this system.

\subsection{Effect of Initial Water Content on the Esterification Reaction}

Since the molecular sieves was not required in our reaction system, the effect of initial water content on the esterification reaction was also investigated (Fig. 5). When initial water contents $(V: V)$ were $2 \%$ and $5 \%$, it had slight influence on the beginning reaction rate (or the reaction time to equilibrium). However, the conversion of DHCA and yield of hexyl dihydrocaffeate were influenced significantly when initial water content was more than $5 \%$ (eg. 10\% and 20\%). Therefore, the esterification reaction of DHCA with hexanol could proceed efficiently when initial water content was below $5 \%$, and no extra molecular sieves were used to remove water generated in the esterification reaction process.

\subsection{Kinetics of the Esterification of DHCA with Hexanol}

According to the results in Fig. 3, the conversion of DHCA reached a stable value after $2 \mathrm{~h}$ at $80{ }^{\circ} \mathrm{C}$ or $100{ }^{\circ} \mathrm{C}$. The pseudo-homogeneous model did not have sorption effect on the catalyst in a reactant medium ${ }^{[11]}$. If the reaction mixture was considered as a single liquid phase, the performance of the pseudo-homogeneous model could be considered as a satisfactory method to correlate the esterification of DHCA with hexanol catalyzed by PTSA.

This esterification of DHCA with hexanol is represented as follows:

$$
\mathrm{A}+\mathrm{B} \underset{k_{2}}{\stackrel{k_{1}}{\rightleftharpoons}} k_{1} k_{2} \mathrm{D}+\mathrm{W}
$$

where A is DHCA, B is hexanol, D is hexyl dihydrocaffeate, and $\mathrm{W}$ is water. This reaction can be considered a second order reaction. Therefore, the rate equation can be expressed as follows:

$$
r_{\mathrm{A}}=\frac{\mathrm{d} C_{\mathrm{A}}}{\mathrm{d}_{t}}=k_{1} C_{\mathrm{A}} C_{\mathrm{B}}-k_{-1} C_{\mathrm{D}} C_{\mathrm{W}}
$$

where $C_{\mathrm{A}}, C_{\mathrm{B}}, C_{\mathrm{D}}$ and $C_{\mathrm{W}}$ are the concentrations of DHCA, hexanol, hexyl dihydrocaffeate and water, respectively. $k_{1}$ is the forward rate constant, and $k_{-1}$ is the backward rate constant.

From the relationship of $C_{\mathrm{A}}$ and extent of conversion of DHCA, $X_{\mathrm{A}}$, as well as correlations of the changes in B, D and $\mathrm{W}$ to A. Therefore, Equation (3) can be expresssed as follows:

$$
\frac{\mathrm{d} x_{\mathrm{A}}}{\mathrm{d}_{t}}=C_{\mathrm{A} 0}\left[k_{1}\left(1-x_{\mathrm{A}}\right)\left(M-x_{\mathrm{A}}\right)-k_{-1} x_{\mathrm{A}}^{2}\right]
$$

where $C_{\mathrm{A} 0}$ is the initial concentration of DHCA, $C_{\mathrm{B} 0}$ is the initial concentration of hexanol and $M$ is the concentration ratio of hexanol to DHCA $\left(M=C_{\mathrm{B} 0} / C_{\mathrm{A} 0}\right)$.
At equilibrium, $\mathrm{d} c_{\mathrm{A}} / \mathrm{d} t=0$, the equilibrium constant $(K \mathrm{e})$ can be calculated as follows:

$$
K_{\mathrm{e}}=\frac{k_{1}}{k_{-1}}=\frac{x_{\mathrm{Ae}}^{2}}{\left(1-x_{\mathrm{Ae}}\right)\left(M-x_{\mathrm{Ae}}\right)}
$$

$X_{\mathrm{Ae}}$ is the conversion of DHCA at equilibrium stage, and $K_{\mathrm{e}}$ is the equilibrium constant.

If Equation (4) is integrated and rearranged, Equation (5) in its linear form is expressed as follows

$$
\operatorname{In}\left[\left(\frac{2 a_{1} x_{\mathrm{A}}-M-1-a_{2}}{2 a_{1} x_{\mathrm{A}}-M-1+a_{2}}\right)\left(\frac{-M-1+a_{2}}{-M-1-a_{2}}\right)\right]=a_{2} k_{1} c_{\mathrm{A} 0} t
$$

where

$$
\begin{aligned}
& a_{1}=1-\frac{1}{K_{\mathrm{e}}} \\
& a_{2}=\left[(M+1)^{2}-4 a_{1} M\right]^{1 / 2}
\end{aligned}
$$

The results of plotting the left-hand-side of Equation (5) vs. reaction time $(t)$ were presented in Fig. 6, from which it could find that straight lines passing through the origin were obtained. All straight lines gave a good linear correlation lying in the $R^{2}$ range of $0.973-0.992$, which clearly showed that the proposed kinetic model was appropriate for this reaction. The forward reaction rate constant $\left(k_{1}\right)$ was obtained from the slope of lines in Fig. 6 at different reaction temperatures.

The dependence of $k_{1}$ on the reaction temperature is described by Arrhenius Law, as given in Equation (6):

$$
k_{1}=A \mathrm{e}^{-E / R T}
$$

where, $A$ is pre-exponential factor, $E$ is activation energy, $R$ is idea gas constant and $T$ is reaction temperature $(\mathrm{K})$.

The activation energy was $22.6 \mathrm{~kJ} / \mathrm{mol}$, which confirmed that PTSA possesses a high catalytic activity in the esterification of DHCA with hexanol to synthesis of hexyl dihydrocaffeate. In the previous report ${ }^{[12]}$, the activation energy was $17.5 \mathrm{~kJ} / \mathrm{mol}$ when esterification of caffeic acid with methanol was also promoted by PTSA. The above results indicated that PTSA is an efficient catalyst for esterification.

\subsection{Esterification of Other Phenolic Acids}

It has been reported that alkyl esters of phenolic acids, especially propyl caffeate, has stronger antioxidant activity than caffeic acid or other alkyl esters $^{[8]}$. With our optimized reaction conditions, the scope of esterification of various phenolic acids with propanol was investigated, and the results were summarized in Table 1. In general, yields of esterification of phenolic acids $(1 \mathrm{a}-1 \mathrm{j})$ with propanol were good to excellent $(85 \%-93 \%)$. Dihydrocaffeic acid (1a) and 3-(4-hydroxyphenyl) propanoic acid (1b) took place esterification with propanol smoothly and afforded the corresponding esters $(2 \mathrm{a}-2 \mathrm{~b})$ in $88 \%$ and $87 \%$ yields, respectively (Table 1 , entry 1 -entry 2 ). And a set of phenolic acids (1c-1f) based on cinnamic acid were introduced into the esterification reactions, and electron-rich phenolic acids (1c-1e) exhibited good reactivity with isolated yields of $85 \%-88 \%$ (Table 1, entry 3-entry 5). In addition, gallic acid (1g) and related phenolic acids $(1 \mathrm{~h}-1 \mathrm{j})$ were also efficient under the same reaction conditions and produced the corresponding esters in $88 \%-93 \%$ yields (Table 1 , entry 7 -entry 10 ). The above results indicated that such reaction condition was suitable for lipophilization of phenolic acids with fatty alcohols. 


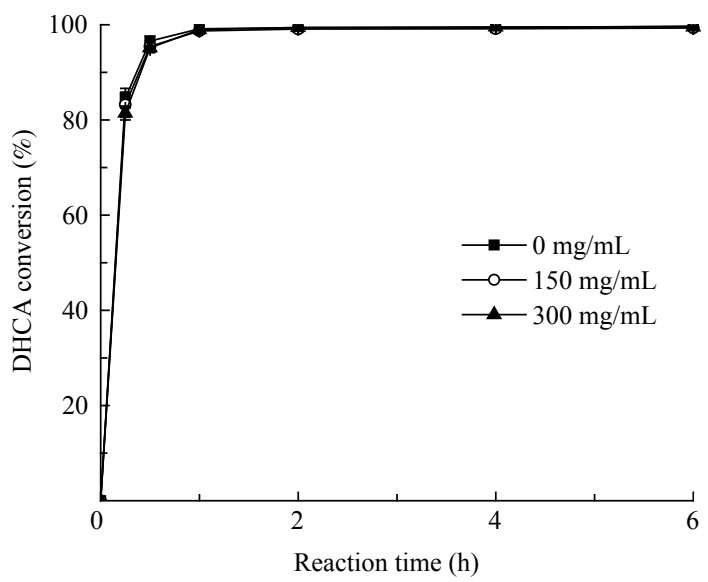

b

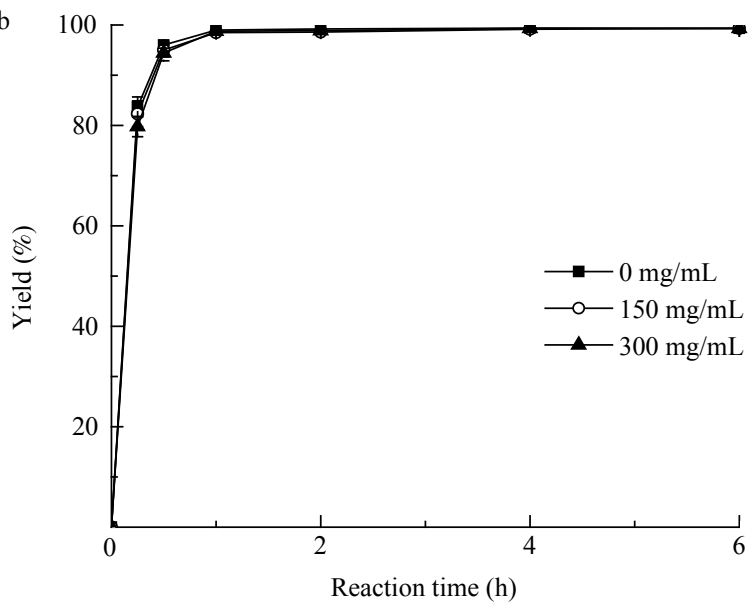

Fig. 4 Effect of molecular sieve amount on the conversion of DHCA and yield of hexyl dihydrocaffeate Reaction conditions: PTSA $1 \%$, DHCA $1.0 \mathrm{mmol}$, hexanol $30.0 \mathrm{mmol}, 80^{\circ} \mathrm{C}$.

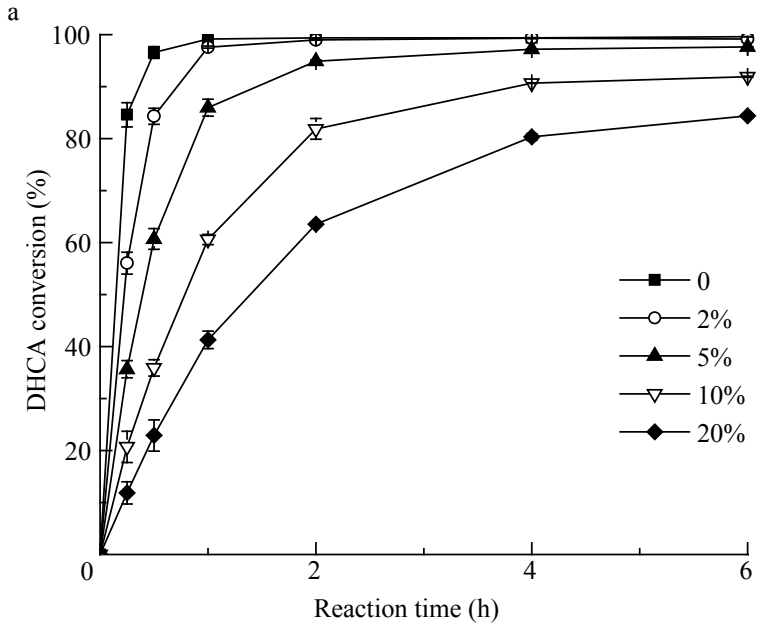

b

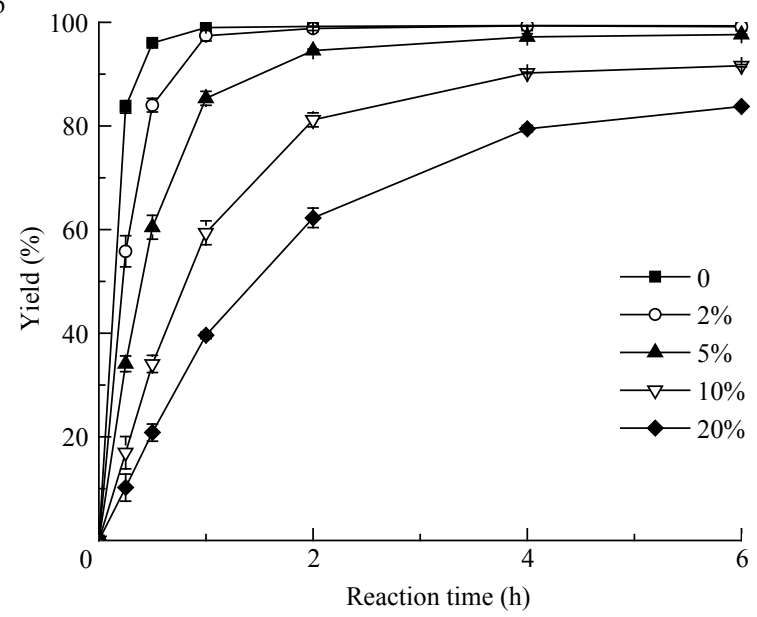

Fig. 5 Effect of initial water content on the conversion of DHCA and the yield of hexyl dihydrocaffeate Reaction conditions: PTSA $1 \%$, DHCA $1.0 \mathrm{mmol}$, hexanol $30.0 \mathrm{mmol}, 80^{\circ} \mathrm{C}$.

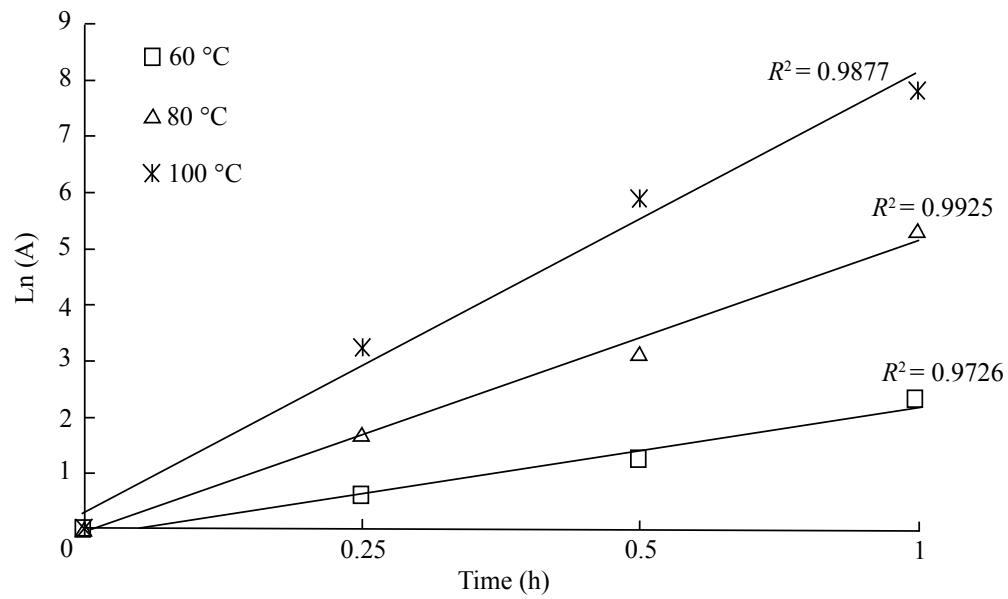

Fig. 6 Second order reversible model for the calculation of reaction rate constants at different temperatures 
Table 1 PTSA-catalyzed esterification of phenolic acids with propanol ${ }^{\mathrm{a}}$

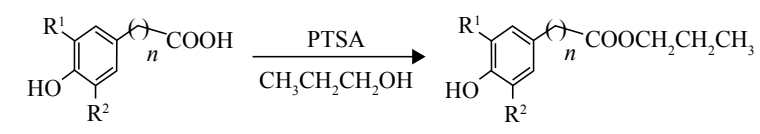

Ester (2) Yield (\%)

Note: a Reaction conditions: 1 (1.0 mmol), $\mathrm{CH}_{3} \mathrm{CH}_{2} \mathrm{CH}_{2} \mathrm{OH}$ (30 mmol), PTSA $(1.0 \%), 90^{\circ} \mathrm{C}, 2-4 \mathrm{~h}, \mathrm{~N}_{2} .{ }^{\mathrm{b}}$ Isolated yield based on $\mathbf{1}$.

\section{Conclusions}

The reaction conditions and kinetic parameters for the efficient synthesis of hexyl dihydrocaffeate by esterification of DHCA and hexanol using PTSA as a catalyst were investigated. To evaluate the effects of synthesis parameters on the esterification process, the catalyst loadings, reaction temperature, molar ratio of substrates, amount of molecular sieves and initial water content were taken into account. The highest yield of hexyl dihydrocaffeate was achieved under the optimum as follows: 1 mol\% PTSA, a 1:30 molar ratio of dihydrocaffeic acid to hexanol without molecular sieves at $80^{\circ} \mathrm{C}$ in $2 \mathrm{~h}$. The relationship between temperature and the forward rate constant gave the activation energy of $22.6 \mathrm{~kJ} / \mathrm{mol}$, which indicated that PTSA possesses a high catalytic activity in the esterification of DHCA with hexanol to synthesis of hexyl dihydrocaffeate. Importantly, this reaction system could proceed efficiently when initial water content below 5\%. In addition, a set of phenolic acids could take place esterification reaction efficiently under the same conditions and afford the corresponding esters in good to excellent yields, which indicated that this developed method was suitable for lipophilization of phenolic acids with fatty alcohols.

\section{Conflict of Interest}

The authors declare that there is no conflict of interest.

\section{References}

[1] YANG S Y, HONG C O, LEE G P, et al. The hepatoprotection of caffeic acid and rosmarinic acid, major compounds of Perilla frutescens, against t-BHP-induced oxidative liver damage[J] Food and Chemical Toxicology, 2013, 55(3): 92-99.

[2] RAO C V, DESAI D, KAUL B, et al. Effect of caffeic acid esters on carcinogen-induced mutagenicity and human colon adenocarcinoma cell growth[J]. Chemico-Biological Interactions, 1992, 84(3): 277-290.

[3] CHEN H C, TWU Y K, CHANG C J, et al. Optimized synthesis of lipase-catalyzed octyl caffeate by Novozym 435[J]. Industrial Crops and Products, 2010, 32(3): 522-526.

[4] UWAI K, OSANAI Y, IMAIZUMI T, et al. Inhibitory effect of the alkyl side chain of caffeic acid analogues on lipopolysaccharide-induced nitric oxide production in RAW264.7 macrophages $[\mathrm{J}]$. Bioorganic \& Medicinal Chemistry, 2008, 16(16): 7795-7803.

[5] FIUZA SM, GOMES C, TEIXEIRA L J, et al. Phenolic acid derivatives with potential anticancer properties-a structure-activity relationship study. Part 1: methyl, propyl and octyl esters of caffeic and gallic acids[J]. Bioorganic \& Medicinal Chemistry, 2004, 12(13): 3581-3589.

[6] YANG Z, GUO Z, XU X B. Ionic liquid-assisted solubilization for improved enzymatic esterification of phenolic acids[J]. Journal of the American Oil Chemists' Society, 2012, 89(6): 1049-1055.

[7] YANG Z, GUO Z, XU X B. Enzymatic lipophilization of phenolic acids through esterification with fatty alcohols in organic solvents[J]. Food Chemistry, 2012, 132(3): 1311-1315.

[8] PANG N, GU S S, WANG J, et al. A novel chemoenzymatic synthesis of propyl caffeate using lipase-catalyzed transesterification in ionic liquid[J]. Bioresource Technology, 2013, 139(13): 337-342.

[9] DE PINEDO A T, PEÑALVER P, RONDÓN D, et al. Efficient lipase-catalyzed synthesis of new lipid antioxidants based on a catechol structure[J]. Tetrahedron, 2005, 61(32): 7654-7660.

[10] BAGHERNEJAD B. Application of p-toluenesulfonic acid (PTSA) in organic synthesis[J]. ChemInform, 2012, 43(7): 1522-2667.

[11] SANTHANKRISHNAN A, PEEREBOO L, MILLER D J, et al. Measurement of $p$-toluenesulfonic acid-catalyzed reaction kinetics of 1,2-propylene glycol acetylation using in situ H-1 NMR spectroscopy[J]. Industrial and Engineering Chemistry Research, 2013, 52(27): 9337-9342.

[12] WANG J, GU S, PANG N, et al. A study of the esterification of caffeic acid with methanol using $p$-toluenesulfonic acid as a catalyst[J]. Journal of the Serbian Chemical Society, 2013, 78(7): 1023-1034.

[13] LIU W, HAN L. Lipophilisation of caffeic acid through esterification with propanol using water-tolerable acidic ionic liquid as catalyst[J]. Journal of Oleo Science, 2015, 64(12): 1297-1305. 